\title{
VARIAÇÕES SOBRE UM ENCONTRO: JACQUES DERRIDA E ABDELKEBIR KHATIBI (SE) COR-RESPONDEM
}

\author{
Maria Angélica Deângeli
}

Les mots de l'amitié précèdent, toujours, l'amitié, comme si celle-ci, pour se manifester, attendait d'être annoncée.

(Edmond Jabès)

A partir de um título que nomeia no ato de sua inscrição o encontro - e não se trata de um encontro qualquer - e a correspondência como forma recíproca de resposta (e também de encontro) do um ao outro; a propósito desse título, poderíamos avançar algumas possibilidades de escrita, ou seja, de um desenvolvimento textual que levasse em conta todos esses apelos: o encontro ele próprio, a correspondência desse encontro e toda correspondência de modo geral; os protagonistas desta cena, a saber, Jacques Derrida e Abdelkebir Khatibi; e as variações que essa mesma cena comporta. Enfim, para justificarmos esse título a título de leitura e de correspondência também com os leitores, poderíamos aventurar-nos por vários caminhos que, no traçado de seus contornos, correriam o risco de se cruzar ou não, fícando o encontro e a correspondência para sempre comprometidos e anunciando, de antemão, a incerteza e, talvez, a própria impossibilidade de todo encontro e de toda correspondência.

Não abandonamos, de fato, as vias dessa empreitada textual que é, antes de tudo, um apelo do título, em nome do título que também traz o número desta revista, ou seja, "Tradução e Literatura em correspondência", com os itálicos que marcam a diferença e singularidade daquilo que pode supor qualquer "correspondência"; não renunciamos aos desafios lançados pelo título deste trabalho que, em sua trama, já desestabiliza as palavraschave desse encontro e multiplica seus efeitos de sentido, como, por exemplo, na quebra do prefixo "co" em co(r)-responder e na inserção dos parênteses que pontuam o pronome "se", sugerindo que a reciprocidade da correspondência pode estar provisoriamente suspensa ou que há um "em suspenso" em seu percurso; enfim, os desvios de tal título, nesse jogo de adulteração e de "inclusão", apontam para a complexidade daquilo que pretende estar "em correspondência".

Se, por um lado, não descartamos nenhuma dessas invocações, que nos convocam em ato para testemunharmos a cena do encontro de dois pensadores que, em momentos diferentes e situações diversas, sempre (cor)responderam ao chamado do outro (e de todos os outros), 
decidimos, por outro lado, começar por uma data, por aquilo que precede, e também sucede, todas as variações desse encontro, a supor que tenha havido uma data para essa história de cor-respondência, para essa resposta de um ao outro, resposta permeada por muitos outros. Trata-se, então, de uma história de data e de coração, pois no cerne da cor-respondência, o coração também fala; aliás, é o coração quem fala. Palavra de filiação latina (em coração encontramos cor, cordis), o coração sempre esteve presente no diálogo desses amigos, no enlace dessa cor-respondência que já se anunciava na contramão de qualquer data, antes mesmo da correspondência propriamente dita, dos encontros e das respostas.

Siscar (2005), em um artigo intitulado "O coração transtornado", propõe uma leitura do pensamento derridiano a partir da problemática do coração. Numa espécie de endereçamento direto a Derrida, ele diz:

Como ter coragem de falar a Derrida, de falar sobre ele diante dele, mais uma vez, correndo inevitavelmente o risco de ousadia e ingratidão? Como ter coragem de reaprender a lê-lo, de renomear o outro diante dele e, assim, o percurso é sempre aquele traçado pela tradução. Mas os desejos e arroubos da tradução são, também, um aspecto importante da leitura de Derrida. Como falar de Derrida, hoje, senão com o coração? (Siscar 2005: 135, grifo meu).

Como, parafraseando Siscar, falar de Derrida e de Khatibi, de tradução e de correspondência, de língua e de literatura, de encontro e de amizade, senão com o coração? Pelas vias do coração e de todos os sentimentos a ele intimamente ligados?

O apelo está lançado. Quem ousaria resistir ao chamado de um amigo que fala com o coração e, para entrarmos no jogo da tradução (que não deixa de ser outra história de coração), de tout coeur? Nesse apelo estão implícitos a paixão e o martírio, a paixão martirizante daqueles que se encontram para testemunharem suas próprias histórias em nome de uma outra história, mais trágica talvez, que dilacera o coração. Martírio e paixão permeiam, assim, a cena do testemunho e da correspondência ou da cor-repondência das testemunhas; pois em mártir, do grego martus, marturos, está presente a testemunha, aquela que se tornará um mártir, como lembra Derrida, "a testemunha da fé" (Derrida 2004b: 527).

Enfim, muitas histórias, história da história, história e histórias, interpõem-se no que pretendemos nomear como o encontro Derrida-Khatibi. Várias histórias e várias datas. Comecemos, então, por designar a data que parece selar tal encontro, a data e o lugar, já que uma data sempre dirá respeito também a um lugar (Derrida 1986).

Setembro de 1974. Paris. Não por acaso Paris, a "Metrópole", a "pátria mãe", palavras que se repetirão inúmeras vezes no discurso desses amigos, na narrativa de suas histórias; amigos à distância, mas não distantes, escrevendo sobre assuntos de interesse 
comum, testemunhando em seus próprios nomes a história particular que foi a colonização francesa no Magrebe.

Na introdução de um livro publicado em 2007 e intitulado Jacques Derrida en effet, obra que reúne uma série de textos dedicados ao amigo Derrida, Khatibi escreve ${ }^{1}$ :

Nós nos encontramos, Jacques Derrida e eu, em setembro de 1974, em Paris, num café na Praça Saint-Sulpice. [...] A partir desta data, e até sua morte em outubro de 2004, mantivemos uma relação mais ou menos contínua, amigável e fiel, como um ponto de referência no tempo a ser vivido. Éramos amigos que vivíamos à distância; ele, do lado de Paris; e eu, do lado de Rabat. Ele viajava e trabalhava muito no exterior. Sua importância intelectual, no mundo, não precisa mais ser demonstrada. [...] Ela viaja no tempo, graças à tradução; de minha parte, iniciei a tradução de sua obra em árabe (Khatibi 2007a: 7, grifos meus). ${ }^{2}$

"A partir desta data" (mas também antes dela), em Paris (mas também em outros lugares), a partir de Paris, ou da Argélia ou do Marrocos, podemos narrar a história dessa amizade que fala principalmente de língua e de tradução, de língua e de colonização, história muitas vezes lembrada por Khatibi que iniciou, quanto a ele e também até a sua morte em março de 2009, em algum momento, a tradução de Derrida em árabe. Gesto incalculável de amigo.

De fato, acontecimento tão bem assinalado por Khatibi, a importância intelectual de Derrida, no mundo, "não precisa mais ser demonstrada", pois sua obra "viaja", às vezes à maneira de um errante, de país em país, de língua em língua, entre as línguas, de cultura em cultura, para além das fronteiras, "graças à tradução", por meio da tradução, ao que acrescentaríamos, também, graças aos tradutores e tradutoras, a quem Derrida sempre confessou sua dívida impagável, como ele próprio afirma:

Se ouso abordar esse tema diante de vocês é porque a falta de coragem, a renúncia precoce da qual falo e de onde parto, essa confissão de falência diante da tradução, foi sempre em mim a outra face de um amor ciumento e admirativo: paixão por aquilo que, endividando-se infinitamente com tradução, apela, ama, provoca e desafia; admiração por aqueles e aquelas que considero os únicos a saber ler e escrever: as tradutoras e tradutores (Derrida 2000:14). ${ }^{3}$

\footnotetext{
${ }^{1}$ Todas as traduções dos excertos em francês são minhas, salvo indicação em contrário.

${ }^{2}$ Nous nous sommes rencontrés, Jacques Derrida et moi, en septembre 1974, à Paris, dans un café de la place Saint-Sulpice. [...] Depuis cette date et jusqu'à son décès en octobre 2004, nous avions entretenu une relation plus ou moins continue, amicale et fidèle, comme un point de repère dans le temps à vivre. Nous étions des amis qui vivions à distance; lui, à côté de Paris; et moi, à côté de Rabat. Il voyageait et travaillait beaucoup à l'étranger. Son importance intellectuelle sur le plan international n'est plus à démontrer. [...] Elle voyage dans le temps, grâce à la traduction; et pour ma part, j'ai initié sa traduction en langue arabe (Khatibi 2007a: 7).

${ }^{3}$ Para esse texto em particular, "O que é uma tradução 'relevante'”, pela sua temática e pelo apelo explícito aos múltiplos gestos de tradução que nele se apresentam, nos serviremos da tradução de Olívia Niemeyer Santos (Alfa, 2000, 44, p. 13-44), a quem reconhecemos aqui também nossa dívida de leitores.
} 
Derrida reconhece sua dívida para com os tradutores, confessa sua paixão por este algo (a tradução) que desafia, provoca, faz aumentar a dívida, numa espécie de economia em que nada se quita, numa lógica de dívida sobre dívida que, no entanto, implica uma história de amor, bem perto do coração, e que só pode ser apreendida nessa outra "lógica" do tout coeur. Derrida reconhece também o gesto do amigo Khatibi, aquele que o traduz no mundo árabe, aquele que "poucos" conhecem; pois, se por um lado, o nome de Derrida dispensa as formalidades de apresentação, por outro, o nome de Abdelkebir Khatibi aparece quase como uma incógnita. Filósofo, escritor e poeta marroquino de língua francesa e também de língua árabe, a obra de Khatibi é pouquíssimo conhecida na França e muito menos além do Atlântico. O que une, então, um e outro, a saber, um judeu e um muçulmano — para sermos fiéis aos amigos talvez coubesse dizer: um judeu-franco-magrebino, como se autodenomina o próprio Derrida, e outro magrebino, mais precisamente, marroquino de cultura árabemuçulmana - o que os une, além da experiência comum da colonização francesa, dos interesses políticos por questões que sempre estiveram à margem dos poderes dominantes, da amizade selada há anos, num encontro fortuito em Paris, é, sem dúvida, o amor pela língua (língua francesa, diga-se de passagem) pela literatura e pela filosofia ${ }^{4}$.

Nesse encontro de amor com a língua, a literatura e a filosofia francesas, mais precisamente, na descoberta da obra de Derrida, em algum momento, o nome de Khatibi chega até nós, nos chega, como ele próprio dizia, como "um estrangeiro profissional" (Khatibi 1997), decidido a permanecer na estrangeiridade da letra e da escritura, a errar de idioma em idioma.

Encontro sobrepondo-se a encontro, datas sobre datas, lugares sobre lugares, línguas sobre línguas, tudo nos encaminha para a cena de uma outra revelação (e de outra tradução).

\footnotetext{
${ }^{4}$ Se a questão das origens, mais precisamente, das filiações, parece nomeada (e nomeável) de maneira menos enigmática para Khatibi, embora ele não deixe de evocar as desordens identitárias que pode desencadear o duplo pertencimento, de um lado, à cultura magrebina, árabe-muçulmana, e, de outro, à cultura "franco-francesa", a essa divisão que se estabelece aleatoriamente entre Oriente e Ocidente (ver, principalmente, a esse respeito sua obra: La mémoire tatouée: autobiographie d'un décolonisé (1974/2007b), para Derrida, a história de suas supostas filiações parece não se esclarecer nunca. Em Le monolinguisme de l'autre (1996), Derrida apresentase como o "mais franco-magrebino" dentre todos os franco-magrebinos, inclusive o próprio amigo Khatibi, que é também chamado, por Derrida, de "franco-magrebino". No entanto, essa genealogia torna-se mais complexa quando a designação franco-magrebina vem acompanhada da palavra judeu, formando, assim, um novo sintagma: Jacques Derrida um/o judeu-franco-magrebino (e essa é toda a história narrada em Le monolinguisme de l'autre). A alusão a essa judeidade, mesmo se, algumas vezes e em algumas ocasiões, Derrida manifestou-se sobre esse traço do ser "judeu" em sua história, tal referência permanece "em suspenso", há um silenciamento quanto ao fato do que essa judeidade pode, efetivamente, evocar. Podemos perguntar-nos o que se esconde (e o que se mostra) sob a designação de um judeu-franco-magrebino, mais precisamente, de um judeu da Argélia. Qual a origem dessa e para essa judeidade na história de Jacques Derrida? Essas e tantas outras questões são silenciadas, condenadas ao não-dito e, muitas vezes, aparecem como "restos" de algo que não se resolveu (e não se resolve nunca) na trama dessa complexa genealogia.
} 
Abril de 1992. Louisiana, Estados Unidos. Num colóquio anunciando-se sob o duplo título de Echoes from Elsewhere/Renvois d'Ailleurs, cujo propósito era discutir questões referentes à "francofonia fora da França", Derrida evoca, inúmeras vezes, em sua conferência, o amigo Khatibi. Apelo público e explícito feito em nome de uma amizade selada pelo amor à língua. Língua francesa, para Derrida, única e insubstituível, sem a qual ele se sente perdido, “mais exilado do que nunca" (Derrida 2002: 23). Língua francesa, também para Khatibi, no entanto, língua dividida entre o próprio e o estrangeiro, entre-dois, ou, nas palavras do autor, entre-três:

Situação eminentemente complexa, pois, língua terceira, o francês substitui-se à diglossia, traduzindo-se a si próprio do francês para o francês. Ponto nodal [...] que faz que o bilinguismo interno a toda língua (o do comunicável ao incomunicável, da "prosa" à poesia) opere uma separação, um ato de cisão, de diferença e de transmutação, segundo um movimento que não cessa de se dobrar e de se desdobrar (Khatibi 1985: 179). ${ }^{5}$

O francês substitui-se à diglossia existente entre o árabe clássico e o dialetal, mas ao operar tal substituição, a língua francesa também traz consigo as marcas dessa diglossia, traduz o francês (certo tipo de francês) em (outro) francês, já que o bilinguismo é um processo inerente a toda língua. Processo que institui a cisão, a separação, a ruptura no coração da língua, num movimento que, incessantemente, se dobra (se double) e se desdobra (se dédouble).

Um gesto de amizade encena, então, o texto do(s) amigo(s), do amigo Derrida que se dirige ao amigo Khatibi, numa cena tomada pelo diálogo entre as línguas. Diálogo em forma de monólogo do qual Khatibi seria uma espécie de co-autor.

O texto de Derrida, Le monolinguisme de l'autre: ou la prothèse d'origine, objeto da conferência em Louisiana, aparece sob forma de livro, pelas edições Galilée, em $1996^{6}$. Da epígrafe ao epílogo, a referência explícita e implícita ao amigo Khatibi, mais precisamente, a dois textos que dialogam diretamente com Le monolinguisme de l'autre, a saber: Amour Bilingue, publicado inicialmente em 1983, pela editora Fata Morgana ${ }^{7}$ e Du bilinguisme, de

\footnotetext{
${ }^{5}$ Situation éminemment complexe, car la langue tierce, le français se substitue à la diglossie en se traduisant luimême du français en français. Point nodal [...] et qui fait que bilinguisme interne à toute langue (celui du communicable à l'incommunicable, de la "prose» à la poésie) opère une séparation, un acte de scission, de différence qui ne cesse de se doubler et de se dédoubler (Khatibi 1985: 179).

${ }^{6} \mathrm{Na}$ página onze do referido livro, numa nota que antecede a página dedicada às epígrafes, lê-se que um primeiro esboço dessa comunicação já havia sido apresentado em um congresso realizado na Sorbonne e organizado por Christine Buci-Gluksmann. No entanto, fato bastante curioso para encontros desse gênero, a data de tal evento não é explicitada.

${ }^{7}$ A edição de Amour Bilingue a que faremos referência data de 1992 e trata-se de uma publicação das Éditions Eddif, do Marrocos. Reda Bensmaïa, num trabalho intitulado “Traduire ou 'blanchir' la langue” (1987),
} 
1985, obra coletiva organizada por Khatibi, por ocasião de um congresso realizado em Rabat, em 1981, sobre questões relativas ao bilinguismo. Quase dez anos, e um pouco mais de dez anos, separam o aparecimento de um texto do outro, ou seja, do percurso que se inaugura com o bilinguismo de Khatibi e que caminha rumo ao monolinguismo do outro de Derrida.

O que se dá a ler de um texto a outro? Como apreender a intersecção do bilinguismo no rastro do monolinguismo? Como responder (e cor-responder) ao apelo do amigo? O que nos dizem esses exercícios de testemunhos, como correspondências de amizade, sobre a língua, a língua do outro, a bi-língua e a monolíngua?

Comecemos, então, com Derrida que, num dia de congresso, em Louisiana, anuncia, logo de início, o pensamento que atravessará todas as reflexões em torno de Monolinguisme de l'autre, a saber, que "ele", sujeito monolingue, só tem uma língua e que, além do mais, essa língua não lhe pertence; propósito que se enuncia nas seguintes palavras: "Eu só tenho uma língua, ela não é minha" (Derrida 1996: 13) ${ }^{8}$.

É preciso imaginar tal sujeito, pensar na sua condição de monolinguismo e de privação, pois a única língua que esse sujeito acredita falar não é sua, ao que ele acrescenta: “Ora, nunca esta língua, a única que estou, assim, destinado a falar, enquanto falar me será possível, em vida em morte, essa única língua, veja você, nunca será minha. Nunca o foi, na verdade" (p. 14). ${ }^{9}$

No imperativo "veja você" (vois-tu), a incidência implícita de um vocativo: "veja você, ó amigo", e não se trata de um amigo qualquer, mas de um bom e fiel amigo, que, entre tantos outros presentes no congresso, compartilha com Derrida a singularidade de uma condição: a de ser franco-magrebino. Condição de um destino, "um estatuto quanto à língua e à cultura", num certo "Estado", como afirma Derrida:

Entre todos os participantes do congresso, dois deles, Abdelkebir Khatibi e eu mesmo, que além de uma antiga amizade, ou seja, a sorte de tantas outras coisas da memória e do coração, compartilham também um certo destino. Eles vivem, quanto à língua e à cultura, num certo "estado": eles têm um certo estatuto. A esse estatuto, naquilo que se nomeia desta forma e que é exatamente "meu país", dão o título de "franco-magrebino" (1996: 26, grifo meu). ${ }^{10}$

\footnotetext{
discute, de maneira bastante minuciosa, a problemática da publicação de Amour Bilingue pela editora francesa Fata Morgana.

${ }^{8}$ Je n'ai qu'une langue, ce n'est pas la mienne (Derrida 1996:13).

${ }^{9}$ Or jamais cette langue, la seule que je sois ainsi voué à parler, tant que parler me sera possible, à la vie à la mort, cette seule langue, vois-tu, jamais ce ne sera la mienne. Jamais elle ne le fut en vérité (Derrida 1996: 14).

${ }^{10}$ Parmi tous les participants du congrès, il en fut deux, Abdelkebir Khatibi et moi-même, qui, outre une vieille amitié, c'est-à-dire la chance de tant d'autres choses de la mémoire et du coeur, partagent aussi un certain destin. Ils vivent, quant à la langue et à la culture, dans un certain «état»: ils ont un certain statut. Ce statut, dans ce qui se nomme ainsi et qui est bien «mon pays», on lui donne le titre de franco-maghrébin (Derrida 1996: 26).
} 
Dentre os inúmeros acontecimentos compartilhados por Derrida e Khatibi, não poderíamos deixar de voltar-nos paras as coisas da "memória e do coração", o que, num outro sintagma, exibindo o curso de sua tradução e operando como uma tradução em curso, poderse-ia ler como "les choses du par coeur et du tout coeur". O coração ainda fala, guarda na memória as coisas do passado colonial, da imposição de um estatuto que lhes é peculiar e que se convencionou chamar franco-magrebino. Se não se pode falar de uma unidade histórica de colonização francesa no Magrebe, pois, no contexto particular de cada país, a colonização tomou rumos diferentes, o imperativo da língua francesa, ou seja, a imposição da língua da metrópole aos países colonizados parece ser o único denominador comum aos chamados franco-magrebinos, e, ainda, torna-se necessário distinguir a condição específica de cada grupo no interior do grupo "mais geral" dos tais franco-magrebinos. É preciso levar em conta a situação dos árabes autóctones, também chamados indigènes, dos judeus árabes e dos judeus berberes, daqueles também oriundos de vários países da Europa, dos colonos franceses, das populações provenientes da Espanha, dos turcos, enfim, das múltiplas etnias que compõem cada um dos referidos Estados.

Derrida fala do caso particular, do exemplo específico, singular, mas também universal, ou singular porque universal, dos judeus "franco-magrebinos" da Argélia. Khatibi testemunha em nome dos árabes, mais especificamente, de tradição muçulmana, do Marrocos. No intervalo e na intersecção de uma história e de outra, vê-se irromper a língua como fio condutor dessas narrativas singulares que perpassam o monolinguismo de um e o bilinguismo do outro.

É a divergência dessas histórias, como divergência da própria história, que permite a Derrida nomear-se publicamente, num dia de congresso em Louisiana, mais franco-magrebino do que o amigo franco-magrebino, Abdelkebir Khatibi, tal como aparece em seu texto:

\footnotetext{
Suponhamos que, sem querer magoar Abdelkebir Khatibi, num dia de colóquio em Louisiana, longe da casa dele e longe da minha casa, longe de nós mesmos também, eu lhe faça uma declaração, pela fiel e admirativa afeição que tenho por ele. $\mathrm{O}$ que lhe declararia esta declaração pública? Isto, mais ou menos: "Caro Abdelkebir, veja você, eu me considero aqui como o mais franco-magrebino de nós dois, e, talvez, mesmo o único franco-magrebino. Se eu estiver equivocado, se eu me enganar ou enganar, aí então, tenho certeza de que vão me contradizer. Tentarei, assim, me explicar ou me justificar da melhor forma possível. Olhemos à nossa volta e classifiquemos, dividamos, procedamos por conjuntos..." (Derrida 1996: 29). ${ }^{11}$
}

\footnotetext{
11 Supposons que, sans vouloir blesser Abdelkebir Khatibi, un jour de colloque en Louisiane, loin de chez lui et loin de chez moi, loin de chez nous aussi, je lui fasse une déclaration, à travers la fidèle et admirative affection que je lui porte. Que déclarerait-il cette déclaration publique? Ceci, à peu près: "Cher Abdelkebir, vois-tu, je me considère ici le plus franco-maghrébin de nous deux, et peut-être même le seul franco-maghrébin. Si je me trompe, si je m'abuse ou si j'abuse, eh bien, je suis sûr qu'on me contredira. Je tenterais alors de m'expliquer
} 
"Sem querer magoar Abdelkebir Khatibi", porque as coisas do coração podem machucar, dilacerar, abrir uma cicatriz irreparável; sem magoar, ao contrário, expressando afeição e fidelidade, Derrida diz sentir-se, ao mesmo tempo, próximo e distante de Khatibi. As coisas do coração parecem aproximá-los, mas para além dessas coisas (da memória e do coração) eles estão separados por uma linha visível-invisível própria a todos os mecanismos de controle colonial, por um superlativo que estabelece a diferença entre o "mais" francomagrebino dentre todos os franco-magrebinos; o "mais" e o "único" aparecem como traço de distinção e de exclusão num conjunto sem contornos definíveis.

Se, a partir desse contorno sem contorno e dessa situação incontornável, Derrida parte do pressuposto que a língua não pertence e não há, em seu caso específico, nenhuma língua materna autorizada, pois, tal como aparece em seu relato, ele nunca pôde chamar o francês de "minha língua materna" (1996: 61), Khatibi experimenta uma situação bem diferente, embora partilhe, de certa forma e de maneira paradoxal, o pensamento segundo o qual a língua também não pertence, como ele próprio diz em Amour Bilingue: "A língua não pertence a ninguém, a língua pertence a alguém e sobre alguém eu não sei nada" (Khatibi 1992: 61). ${ }^{12}$

Entre não pertencer a ninguém e pertencer a alguém, entre nada saber sobre alguém, que pode também ser ninguém, surge o abismo das línguas, da bi-língua e da monolíngua, a ruína da tradução ou a tradução como ruína, o questionamento sobre o intraduzível - a traduzir (Derrida 1998), logo, a dúvida (que não deixa de ser uma dívida) sobre o sentido e a "sina” da tradução, tal como assinala Derrida: "(mas talvez, uma tradução seja consagrada à ruína, a essa forma de memória ou de comemoração que se denomina ruína; a ruína talvez seja sua vocação e um destino que ela aceita desde a origem)" (Derrida 2000: 21).

Cabe primeiramente observar os parênteses que abrem e fecham a escrita de Derrida, parênteses pontuados por um "talvez" e por uma "ruína"; talvez uma ruína, pode ser e pode também não ser; há que se verificar — a dúvida encerra-se nesses parênteses: talvez (peutêtre), pode ser (peut être). No entanto, se esse for mesmo o destino e a vocação da tradução, essa ruína a ameaça desde a sua origem. Mas qual seria sua origem? A origem da ruína como origem da tradução? De que origem estamos falando? Qual seria, de fato, a vocação de uma origem que já se destina em ato e como ato de tradução à ruína?

Se evocarmos o percurso da escrita derridiana para aprendermos a origem de todo esse questionamento, repetiríamos aqui, com ele (e também em sua ausência), que a origem já

ou de me justifier du mieux que je pourrais. Regardons autor de nous et classons, divisons, procédons par ensembles...» (Derrida 1996: 29).

${ }^{12}$ La langue n'appartient à personne, elle appartient à personne et sur personne je ne sais rien (Khatibi 1992: 61). 
aparece disseminada em sua própria origem, pois, nos movimentos da desconstrução, a origem implica uma não-origem, um vestígio, um rastro (trace) antes de outro suposto vestígio. A noção de rastro torna-se fundamental para questionar o problema da idealidade da origem. Para pensar o rastro é preciso abandonar o sistema conceitual metafísico-teológico (e também teleológico) e suas implicações dicotômicas, principalmente o eixo que gira em torno das noções de presença e de ausência. A noção de rastro em Derrida evoca o movimento da différance: o rastro anuncia e difere. Anunciando um já-lá (déjà-là), mas, ao mesmo tempo, impedindo (adiando) sua realização absoluta, tal "conceito" coloca a impossibilidade de uma origem pura e de um "fechamento do devir". Todo rastro é rastro de rastro. Como diz Derrida: "O rastro não é somente o desaparecimento da origem, ele quer dizer aqui [...] que a origem nem ao menos desapareceu, que ela não foi constituída senão em contrapartida por uma nãoorigem, o rastro que se torna, assim, a origem da origem" (Derrida 1967: 90). ${ }^{13}$

O questionamento em torno da noção de origem ocupará um espaço significativo na reflexão derridiana sobre a língua e o idioma, pois, nessa disseminação originária, a língua aparece como algo que se empresta ao enxerto (greffe $)^{14}$ em seu próprio corpo, que só existe e resiste enquanto língua sob a condição de ser incessantemente transplantada. Operação de enxerto, mas também de perda, de uma perda disseminada como um dom cindido na origem. Enxerta-se o materno no estrangeiro ou o estrangeiro no materno, o próprio no outro, o traduzível no intraduzível. Enxerta-se e perde-se, como assinala de maneira precisa o amigo Khatibi, enveredando-se pelas vias da disseminação:

Se não existe (como nós o dizemos depois e com outros) a língua, se não existe monolinguismo absoluto, falta delimitar o que é uma língua materna em sua divisão ativa e o que se enxerta entre essa língua e a outra dita estrangeira. Quem se enxerta aí e quem se perde, não pertencendo nem a uma nem a outra: o incomunicável. A bi-língua, em seus efeitos de palavra e de escritura... (Khatibi 1985: 190) ${ }^{15}$

\footnotetext{
${ }^{13}$ La trace n'est pas seulement la disparition de l'origine, elle veut dire ici [...] que l'origine n'a même pas disparu, qu'elle n'a jamais été constituée qu'en retour par une non-origine, la trace qui devient ainsi l'origine de l'origine (Derrida 1967: 90).

${ }^{14}$ A palavra greffe em francês recobre tanto o sentido de enxerto quanto o de transplante. Assim, a língua, na perspectiva derridiana, é sempre uma língua greffée: língua na qual foram enxertadas outras línguas; língua que sofreu uma operação de transplante e que também foi trans-plantada em/para outras línguas. Derrida usa a expressão langue greffée para significar a impossibilidade de uma língua única, pura e apontar para o caráter essencialmente plural da língua. Desta forma, ele diz: “[...] estamos, assim que entramos no jogo, na multiplicidade das línguas e na impureza do limite" (Derrida 2000: 16).

${ }^{15}$ S'il n'y a pas (comme nous le disons après et avec d'autres) la langue, s'il n'y a pas de monolinguisme absolu, reste à cerner ce que c'est qu'une langue maternelle dans sa division active, et ce qui se greffe entre cette langue et celle dite étrangère. Qui s'y greffe et qui s'y perd, ne revenant ni à l'une ni à l'autre: l'incommunicable. De la bi-langue, dans ses effets de parole et d'écriture... (Khatibi 1985: 190).
} 
Não há nem monolinguismo, nem bilinguismo, nem plurilinguismo absolutos. A arte da disseminação, como um ponto de sutura e de ruptura entre as línguas, é o que se desenha na própria trama do texto, no texto permutado, traduzido de uma língua para outra, enxertado de línguas outras. No entanto, essa situação que Khatibi experimenta e conhece tão bem ainda o leva a se perguntar:

\begin{abstract}
Mas em que ponto se trama o gozo do plurilinguismo textual [...]? A partir do momento em que o bilinguismo e o monolinguismo são habitados por um fora (dehors) intraduzível, os autores fazem apelo a fragmentos de outras línguas, como se o texto não devesse retornar a sua própria língua e se multiplicasse rumo a um gozo sempre mais distante, e rumo a um alhures que faz recuar o indizível, o silêncio, a loucura de escrever e a confusão das línguas em seus limites. Falar em línguas é a narrativa dessa loucura sob vigilância (Khatibi 1985: 180). ${ }^{16}$
\end{abstract}

Haveria, então, um gozo do outro como gozo do texto, mas um gozo disseminado entre o próprio e o impróprio, o silêncio e a palavra, o dizível e o indizível, o traduzível e o intraduzível - a traduzir, culminando na loucura de escrever, na "confusão das línguas em seus limites". Institui-se, desta forma, um limite para a loucura e a confusão, uma barra, um interdito (ao gozo, talvez) para além do qual não se é mais permitido errar. Trata-se de uma "loucura sob vigilância" para uma escrita, apesar de tudo em permanente errância e em constante tradução.

As línguas confundem-se, permutam-se, e Khatibi reconhece, nos efeitos dessa permutação, uma perturbação intrínseca permeando o jogo de "uma língua mais a outra", ou de "uma língua menos a outra". É no jogo do "mais um" e do "menos um" que Khatibi responde ao apelo lançado pelo amigo em seu monolinguismo do outro, no palco de um outro encontro.

Fevereiro de 1995. École de Hautes Études en Sciences Sociales, Paris. Ao lado de Derrida e de outros amigos, Khatibi profere uma conferência sob o título de "Lettre ouverte à Jacques Derrida" ${ }^{17}$; tratava-se de responder ou simplesmente comentar as palavras do amigo enunciadas por ocasião do congresso em Louisiana.

Uma "carta aberta" destina-se, então, a um amigo presente; em sua singularidade essa carta aberta possui um destinatário certo, mas não tem destino fixo (Derrida 1980). Remetente

\footnotetext{
${ }^{16}$ Mais où se noue la jouissance du plurilinguisme textuel[...]? Dès que le bilinguisme et le monolinguisme sont hantés par un dehors intraduisible, les auteurs font appel à des fragments d'autres langues, comme si le texte ne devait pas revenir à sa langue propre, et se multipliait vers une jouissance toujours plus écartée, et vers un ailleurs qui fait reculer l'indicible, le silence, la folie d'écrire et la confusion des langues dans leurs limites. Parler en langues est le récit de cette folie sous surveillance (Khatibi 1985: 180).

${ }^{17} \mathrm{O}$ texto de que dispomos da "Lettre ouverte à Jacques Derrida" data de 2004 e foi publicado num número especial da Revue Europe dedicado a Jacques Derrida.
} 
e destinatário apresentam-se, assim, numa mesma cena para discutir o destino (sem destino) e também a vocação de tal carta. No entanto, o que pode dizer, ao amigo, uma carta aberta? Por que uma carta aberta destinar-se-ia a um só sujeito? Ou então: o que nesse sujeito poderia tornar seu exemplo (singular) universalizável? O que dizer, ainda, de uma carta (une lettre) em cuja letra (la lettre), tomada aqui em seu sentido de significante ou enquanto rastro de uma subjetividade, inscrever-se-iam as marcas de um passado comum? E se o passado fosse comum e diferente ao mesmo tempo (à la fois et toutes les fois)?

São inúmeras as questões que atravessam a leitura (e a escrita) dessa carta, a qual se apresenta também sob forma de testamento, tal como diz Khatibi: "Testamento que não pertence a ninguém, como a língua natal. Trata-se de um contrato de reapropriação? Uma assinatura branca? Sem dívida? Dívida sem dívida, é possível? Esta seria, então, a posição ideal para ler com confiança seu texto. Comecemos" (Khatibi 2004: 203) ${ }^{18}$. No entanto, poderíamos, ainda, perguntar-nos: Como ler o texto de um amigo que nos interpela? Como cor-responder a esse apelo? Como dar conta de um testemunho (o testemunho de Jacques Derrida) que evoca uma outra testemunha in loco, a saber, ele próprio Khatibi?

Se Derrida, por um lado, confessa sua dívida impagável para com a tradução, "as tradutoras e tradutores", para com o amigo Khatibi, tradutor de sua obra no mundo árabe, por outro lado, Khatibi prefere partir de um gesto aporético e anunciar a possibilidade de uma "dívida sem dívida" para com o texto do amigo e para com o próprio amigo. Há, sem dúvida, uma dívida - dívida de um passado colonial que não se deixa apagar de tantas memórias e de corações dilacerados, pois a ferida permanece aberta —, mas é preciso pensar, por uma questão de sobrevida (do escritor, do tradutor, do poeta e do amigo), na condição de uma "dívida sem dívida". É preciso também levar em conta essa "assinatura branca" inscrita na página de um passado obscuro, fazendo apelo a outras aporias: assinatura sem assinatura ou mais de uma assinatura? Quem assina essa carta e testemunha esse passado?

Num primeiro exercício de escrita e de cor-respondência, como forma de reconhecimento do testemunho do outro, Khatibi evoca o passado e as diferenças que cercaram o percurso de um e do outro, ou seja, dele e do amigo Derrida, em função da própria historicidade e das particularidades inerentes a cada contexto.

\footnotetext{
18 Testament qui n'appartient à personne, comme la langue, la langue natale. Est-ce un contrat de réappropriation? Une signature blanche? Sans dette? Dette sans dette, est-ce possible? Ce serait là une position idéale pour lire avec confiance ton texte. Commençons (Khatibi 2004: 203).
} 
No Marrocos, contrariamente ao que ocorreu na Argélia, tal como relatado por Derrida em Le monolinguisme de l'autre, a comunidade judaica não perde a cidadania, pelas leis de Vichy. Ela passa de um estado de "proteção" (dhimma), em país muçulmano, a um estado de "Protetorado", durante o período colonial (Khatibi 2004: 205). No entanto, essa proteção salva da morte e da persecução toda uma comunidade que, aparentemente, era bem integrada do ponto de vista social e cultural. As leis da hospitalidade é que definem, segundo Khatibi, os graus de tolerância e intolerância entre os homens e, nesse sentido, o estado marroquino, sob as leis de seu "Protetorado", parecia muito menos intolerante.

Do outro lado da fronteira, o anúncio de um desastre e de um dilaceramento: a experiência sofrida e irreparável da perda da cidadania francesa pelos judeus da Argélia compõe os passos, ritmados sob a lei do outro, de uma história única no mundo.

História da história, compartilhada na violência de seu acontecimento pelos dois amigos magrebinos, ou seja, franco-magrebinos. Lei vinda de fora e dilacerando os laços pessoais e históricos de dentro. Em 1870, sob a III República, pelo "Decreto Crémieux", a França outorga a cidadania francesa aos judeus da Argélia; um ato que procurava exibir as "benesses" da colonização francesa para a população local. Em 1940, menos de um século depois, essa mesma França, sob o governo de Vichy, em nome de um Marechal Pétain, confisca-lhes (aos ditos "judeus magrebinos") a nacionalidade francesa para, logo depois, em 1943, conceder-lhes novamente o estatuto de franceses. Singularidade histórica tão bem narrada por Derrida:

Ora, conheci isso. Com outros, perdi, depois recuperei a cidadania francesa. Perdi-a durante anos sem ter tido outra. Nenhuma sequer, veja você. Não tinha pedido nada. Apenas soube, no momento, que a tinham me tirado... . E depois, num dia, "num belo dia", sem que eu tivesse, mais uma vez, nada pedido, e muito jovem para sabê-lo, com um saber propriamente político, havia recuperado a dita cidadania. [...]. Foi em 1943, eu acho, nunca tinha ido "à França", ainda... (Derrida 1996: 34). ${ }^{19}$

Se Kathibi, por um lado, não experimentou a perda da cidadania, como ocorreu com o amigo Derrida, por outro, as marcas da colonização também estiveram presentes em seu caminho, a começar pelo silenciamento imposto pela língua do outro. Língua silenciosa que o fazia calar, como ele próprio diz:

\footnotetext{
${ }^{19}$ Or j'ai connu cela. Avec d'autres, j'ai perdu puis recouvré la citoyenneté française. Je l'ai perdue pendant des années sans en avoir d'autre. Pas la moindre, vois-tu. Je n'avais rien demandé. Je l'ai à peine su sur le moment, qu'on me l'avait enlevée... . Et puis, un jour, «un beau jour», sans que j'aie une fois de plus rien demandé, et trop jeune encore pour le savoir d'un savoir proprement politique, j'ai retrouvé ladite citoyenneté. [...]. C'était en 1943, je crois, je n'étais jamais encore allé «en France»... (Derrida 1996: 34).
} 
O francês foi, durante minha infância, uma língua silenciosa, reservada à leitura e aos outros exercícios escolares [...]. Era um dever, uma disciplina, uma ascese que nos encerrava num claustro de recolhimento, de dúvida e de desordem. Não se falava com Ninguém (Khatibi 2004: 207). ${ }^{20}$

No entanto, da palavra de silêncio, irrompe o ato poético. De simples exercício escolar a exercício de poesia, de repente, o francês começa a "falar". Não se tratava de substituí-lo à língua materna, mas de dar voz a uma língua de escritura, língua que ele aprendera a escrever antes mesmo que fosse capaz de pronunciá-la, e como "não se fala como um livro" (2004: 208), como diz o autor, tudo estava para ser feito.

Da dessimetria das línguas, surge a aventura da escrita e da tradução ou da escrita como aventura de tradução, não sem embaraçar os traçados da própria história pessoal: uma voz que podia falar, outra que se escrevia sem se falar e se emprestava, assim, aos exercícios de tradução, uma voz que recitava o sagrado e, ainda, uma outra que cantava as lembranças maternas. Superimposição de vozes e de gestos desafiam a identidade do escriba. Uma identidade singular elaborada no traço precioso do cuidado com a língua, língua destinada a narrar a memória e o esquecimento, o estranho e o familiar, a luta e as paixões. Um cuidado especial também é revelado no trato com a sintaxe cuja trama amplia, segundo Kahtibi, o horizonte de hospitalidade em que o escritor passa a ser recebido como convidado em/de seu próprio texto (Khatibi 1999: 38). Um convidado que pode embaralhar as regras do jogo (e) da língua, tal como nos confessa em sua "carta aberta" ao amigo Derrida:

Entretanto, tudo me encorajava a permanecer ilegível, ou seja, um estrangeiro clandestino que navega na noite entre duas línguas. Dizia-se, diz-se, sempre, que a clareza da língua francesa é uma virtude nacional. Ilegível aquele ou aquela que embaralha o princípio de identidade da nação. Ora, eu era colonizado por essa nação (Khatibi 2004: 209). ${ }^{21}$

Khatibi não faz o elogio da ilegibilidade, mas aponta para a necessidade de o escritor intervir na tessitura das línguas, à maneira de "um clandestino que navega na noite entre duas línguas", a fim de multiplicar seus efeitos de criação e de tradução e de desestabilizar os “princípios de identidade”, geradores de modelos absolutos.

\footnotetext{
${ }^{20}$ Le français a été, pendant mon enfance, une langue silencieuse, réservée à la lecture et aux autres exercices scolaires [...]. C'était un devoir, une discipline, une ascèse qui nous enfermait dans un cloître de receuillement, de doute et d'égarement. On ne parlait à Personne (Khatibi 2004: 207).

${ }^{21}$ Pourtant, tout $m$ 'encourageait à rester illisible, c'est-à-dire un étranger clandestin qui navigue dans la nuit entre deux langues. On disait, on dit toujours que la clarté de la langue française est une vertu nationale. Illisible celui ou celle qui brouille le principe d'identité de la nation. Or, j'étais colonisé par cette nation. (Khatibi 2004: 209).
} 
Diante de todos esses desafios, como responder, então, ao amigo? Testemunhar em seu nome no rastro do nome do outro? Falar de bilinguismo ou de monolinguismo? Falar da língua do outro como um dom e uma dívida? Divida de tradução? Dívida sem dívida? Promessa de um dom? Política de uma poética?

Khatibi prefere o caminho da dissidência e da invenção, da dissidência como forma de invenção, pois, para ele, a frase do amigo: "Eu só tenho uma língua, ela não é minha”, é a sentença que possibilita a todo escritor uma forma própria de se inventar em línguas, inventar a língua, "a língua como um rio" que não se deixa domesticar nunca até atingir o mar, num exercício contínuo de desvio e de invenção, de escrita e de tradução. Experiência-limite, quando se trata de, "língua sob língua", narrar o intraduzível do encontro e da separação.

Retomemos, então, a cena inicial que compõe o título deste trabalho: cena de um encontro, constituída pelas mais variadas formas de correspondência entre amigos que (se) escrevem, (se) traduzem, respondem ao chamado de tantos outros amigos, se reconhecem naquilo que designam inevitavelmente como a "língua do outro". No idioma de Jacques Derrida, na bilíngua de Abdelkebir Khatibi, nas tramas do possível-impossível da tradução, no gesto aporético do intraduzível a - traduzir, podemos apreender o enlace de uma amizade também intraduzível tanto nas coisas da memória quanto nos afetos do coração. Há um ritmo, quase inapreensível, capaz de celebrar as variações desse encontro e marcar o compasso de seu acontecimento. É preciso, então, partir desse "ritmo" ou desse "batimento", tal como sugere Derrida:

É preciso talvez, de fato, partir da différance ou do batimento, ao invés [de partir] dos polos da finalização ou da morte. O que está do lado da vida está, então, do lado do batimento? Enquanto bater há vida, e quando não houver mais vida nada mais bate. Não falo do batimento do coração, mas do ritmo, dos ritmos. Então afirmar a vida, dito de outra forma, afirmar o gozo do lado da vida ao invés [de afirmá-lo] do lado da morte, é afirmar o batimento, um ritmo no qual há morte, não uma morte que seja oposta à vida, mas uma morte que está lá, que cisalha a vida, que é o ritmo... (2004a: 61). ${ }^{22}$

Há vida e morte, gozo e sofrimento, na história que se desenha a partir da leitura de Derrida e de Khatibi. No entanto, partimos da vida, do batimento do coração, da paixão (de vida e morte) que perpassa as singularidades dessas escrituras, pois enquanto bater, haverá

\footnotetext{
${ }^{22}$ Il faut peut-être en effet partir de la différance ou du battement, plutôt que des pôles de l'accomplissement ou de la mort. Ce qui est du côté de la vie, est-ce alors du côté du battement? Tant que ça bat il y a de la vie, et quand il n'y a plus de vie ça ne bat même plus. Je ne parle pas du battement du coeur mais du rythme, des rythmes. Alors affirmer la vie, autrement dit affirmer la jouissance du côté de la vie plutôt que du côté de la mort, c'est affirmer le battement, un rythme dans lequel il y a de la mort, non pas une mort qui soit opposée à la vie mais une mort qui est là, qui cisaille la vie, qui est le rythme... (Derrida 2004a: 61).
} 
vida ou, enquanto houver vida, algo baterá; haverá o dito e o não-dito, a palavra e o silêncio, o traduzível e o intraduzível. No toque dessa batida e enquanto houver escrita (ou tradução), perseguiremos os ritmos de Khatibi e Derrida, suas escritas e as complexas tramas de suas histórias e de suas cor-repondências.

\section{Referências bibliográficas:}

BENSMAIA, Réda. Traduire ou «blanchir la langue»: Amour Bilingue d'Abdelkebir Khatibi. In: FAY, M. et al. (Orgs.). Imaginaires de l'autre: Khatibi et la mémoire littéraire. Paris: L'Harmattan, 1987.

DERRIDA, Jacques. De la Grammatologie. Paris: Minuit, 1967. . Le facteur de la vérité. In: La carte postale: de Socrate à Freud et au-delà. Paris: Flammarion, 1980. . Schibboleth: pour Paul Celan. Paris: Galilée, 1986. . Le monolinguisme de l'autre: ou la prothèse d'origine. Paris: Galilée, 1996. . Fidélités à plus d'un: mériter d'hériter où la généalogie fait défaut. In: FORTE, J. (Org). Rencontre de Rabat avec Jacques Derrida: idiomes, nationalités, déconstructions. Paris: Cahiers Intersignes; Casablanca: Éditions Toubkal, 1998. . O que é uma tradução "relevante"? (1999). Tradução de Olívia Niemeyer Santos. Alfa, São Paulo, v. 44, p. 13-44, 2000. Fichus. Paris: Galilée, 2002.

Autour de la langue et du désir. In: SEGARRA, M. (Org.). Lengua por venir/Langue à venir: Seminario de Barcelona. Barcelona: Icaria, 2004a. . Poétique et politique du témoignage. Cahier de l'Herne (organisé et dirigé par M.L. Mallet et G. Michaud), Paris, p. 521-539, 2004b.

KHATIBI, Abdelkebir. In: et al. (Orgs.). Du bilinguisme. Paris: Denoël, 1985. . Amour Bilingue (1983). Casablanca: Ediff, 1992. Un étranger professionnel. Études françaises, v. 33, n.1, p. 123-126, 1997. Le nom et le pseudonyme. In: . La langue de l'autre. New York-Tunis: Les mains secrètes, 1999. . Lettre ouverte à Jacques Derrida. Europe, Paris, n. 901, p. 201-211, 2004. Introduction. In: Jacques Derrida en effet. L'Hay-les-Roses: Al Manar, 2007a. . La mémoire tatouée: autobiographie d'un décolonisé (1974). In: Oeuvres de Abdelkebir Khatibi: I Romans et Récits. Paris: Éditions de la Différence, $2007 \mathrm{~b}$.

SISCAR, Marcos. O coração transtornado. In: NASCIMENTO, Evando (Org.). Jacques Derrida: Pensar a desconstrução. São Paulo: Estação da Liberdade, 2005. 